\title{
An Interpretable Mortality Prediction Model for COVID -19 Patients in Solapur- Maharashtra
}

1 Padmini Habbu, 2 Abdul Kayyum Shaikh*, 3 Vasundhara Deshmukh

1. Department of Biochemistry, Tutor, Ashwini Rural Medical College, Hospital \& Research Centre Kumbhari Solapur. Maharashtra, India. 2. Department of Biochemistry, Professor and HOD, Ashwini Rural Medical College, Hospital \& Research Centre Kumbhari Solapur. Maharashtra. India. 3. Department of Biochemistry, Tutor, Ashwini Rural Medical College, Hospital \& Research Centre Kumbhari Solapur. Maharashtra. India.

*Corresponding author's E-mail: abkayyumsk@gmail.com

Received: 14-10-2020; Revised: 18-12-2020; Accepted: 26-12-2020; Published on: 15-01-2021.

\section{ABSTRACT}

The aim of the study is to find out the causes of mortality in COVID-19 patients of Solapur, to compare the mortality rate of Solapur with patients all over India and the factors affecting the increase mortality rate. Study group included patients with COVID -19 deaths in Solapur, death of COVID-19 with complications like Myocardial infarction, Hypertension, coronary artery disease, Diabetes Mellitus \& Asthma. The morbidity rate was highest in COVID-19 patients with diabetes mellitus (53\%) and hypertension (36\%). The morbidity rate in COVID-19 was also significant in patients with cardiovascular (5.8\%), Asthma (1.4\%) and cerebrovascular disease. The patients with renal and other complications were also affected and the mortality rate was ( $1.8 \%)$ in these patients. Our findings showed that most of the patients who died with COVID-19 were having many other complications. Diabetes mellitus itself contributed fifty three percent, whereas hypertensive patients thirty three percent. Apart from this there were patients with other complications also. This shows that the mortality rate in Solapur was high because of old age and comorbid patients.

Keywords: Solapur Mortality, Comorbidity, Diabetes mellitus.

QUICK RESPONSE CODE $\rightarrow$

DOI:

10.47583/ijpsrr.2021.v66i01.004

DOI link: http://dx.doi.org/10.47583/iipsrr.2021.v66i01.004

\section{INTRODUCTION}

S ince the first report of Coronavirus disease 2019 (COVID-19) in Wuhan, the causative agent, severe acute respiratory syndrome Coronavirus 2 (SARSCoV-2), has undergone rapid global spread within a matter of months. Due to the alarming rates of transmission, the World Health Organization officially declared the situation as a pandemic, with over 80,67, 000 infections and $4,37,296$ deaths worldwide per June 25,2020 . The pandemic continues to place a major strain on the country's resources, and it is predicted that mortality and morbidity rates will become pronounced with the rising spread amongst lower and middle-income countries where healthcare is already at compromisable situation. ${ }^{1,2}$

In India over 3,32,424 infections and about 9502 deaths have been reported. Standard diagnosis of COVID-19 is achieved through molecular identification of the SARSCoV-2 using nucleic acid amplification tests such as the reverse transcriptase-quantitative polymerase chain reaction (RT-qPCR) or viral gene sequencing. In this pandemic period, patient history, hematological and biochemical laboratory parameters and imaging are necessary for the diagnosis. In the Cases of COVID-19 that progress are marked with acute respiratory distress (ARDS) and multi-organ failure, which requiring highly intensive care. In these scenarios, timely detection of disease progression is crucial for appropriate management and intervention. ${ }^{6}$

In India, Maharashtra state is a hotspot for COVID -19, nearly one-third of the total cases in India as well as about $40 \%$ of all deaths. In Maharashtra over 1,10744 infections and about 4128 deaths have occurred. Solapur is a city located in south western region of the Indian state of Maharashtra. Population of Solapur is approximately 9.5 lakhs since then spread of COVID-19 in Wuhan and other parts of world India was lately reported about COVID-19 patients. Till $11^{\text {th }}$ April 20 Solapur was about to be declared as green zone. Suddenly the city has reported $1^{\text {st }}$ corona case on $12^{\text {th }}$ April after a deceased tested positive for contagion, from April $14^{\text {th }}$ onwards when the closed contacts of the decease tested positive, there has been no turning back for the city as there has not been a single day in the reporting of the positive case. Most of the cases reported so far are from congested settlements in Solapur city. The city has been witnessed a surge in severe Acute Respiratory illness (SARI) patients. Latest update with till date $26^{\text {th }}$ June 2020 in Solapur over a 2080 infections patients out of which 1090 recovered 762 are under treatment and unfortunately till this date the deaths rate is 274 .

It is observed that in India COVID -19 mortality rate is $3.29 \%$. In India the states with maximum patients were declared as red zone. Maharashtra was highlight as red spots since beginning because it registered $3.72 \%$ mortality rate. Solapur city was the measure contributor to 
this mortality percentage. From the above observation as Solapur is red zone with maximum mortality rate in the country with $(10.48 \%)$ we planned to conduct a cross sectional study. Hence, our aim was to find out a) the causes of mortality in COVID-19 patients of Solapur, b) to compare the mortality rate of Solapur with patients all over India, c) the factors affecting the increase mortality rate.

\section{MATERIALS AND METHODS}

\section{Study area}

This study was conducted in Ashwini Rural medical college, hospital and research centre Solapur. Maharashtra, over the period of 2 months after taking consent from subjects. Ethical committee approval was obtained for this study.

\section{Study design: cross sectional study}

\section{Inclusive criteria for study group}

Study group included patients with COVID -19 deaths in Solapur, death of COVID-19 with complications like Myocardial infarction, Hypertension, coronary artery disease, Diabetes Mellitus \& Asthma.

\section{Exclusion criteria for study group}

The deaths which occurred in ARMCH \& RC Solapur initially were suspected but on examination were reported COVID19 negative were exclude from study group.

\section{Data Gathering:}

The data of deaths reported in Solapur city as declared by the Municipal corporation was collected and used in this study.

\section{Statistical analysis}

The analysis of data was done by student t test and SPSS17 software.

\section{RESULTS}

Table no.1: The medical information of all deaths patients collected between 12 April to 26 June 2020 was used for model development. In 274 dead patients, fever was the most common initial symptom (96.49\%), followed by cough $(22.80 \%)$, fatigue $(5.7 \%)$, dyspnoea $(3.0 \%)$, chest distress $(1.7 \%)$, and muscular soreness $(1.3 \%)$. The age distribution of the patients was $66.66 \pm 6.8$;years, and 64 $\%$ were male and $35 \%$ female.

It was observed that out of 274 COVID -19 deaths most of patients were with comorbidity and existing illness. The morbidity rate was highest in COVID-19 patients with diabetes mellitus (53\%) and hypertension (36\%). The morbidity rate in COVID-19 was also significant in patients with cardiovascular (5.8\%), Asthma (1.4\%) and cerebrovascular disease. The patients with renal and other complications were also affected and the mortality rate was $(1.8 \%)$ in these patients.
Table 1: Epidemiological, Demographic, Clinical, and Mortality outcome information collected from Medical record

\begin{tabular}{|l|l|}
\hline Characteristics & Overall Mortality rate \\
\hline Age, Mean (S.D) (years) & $66.66(6.83)$ \\
\hline Gender, $\mathbf{n}$ (\%) & \\
\hline Male & $147(64 \%)$ \\
\hline Female & $80(35 \%)$ \\
\hline Symptoms on onset, $\mathbf{n}(\%)$ & \\
\hline Fever & $220(96.49 \%)$ \\
\hline Cough & $52(22.80 \%)$ \\
\hline Fatigue & $13(5.7 \%)$ \\
\hline Dyspnoea & $7(3 \%)$ \\
\hline Chest distress & $4(1.7 \%)$ \\
\hline Muscular soreness & $3(1.3 \%)$ \\
\hline Complications / comorbidity & \\
\hline Myocardial infraction & $16(5.8 \%)$ \\
\hline Hypertension & $100(36 \%)$ \\
\hline Diabetes mellitus & $146(53 \%)$ \\
\hline Asthma & $4(1.4 \%)$ \\
\hline Renal failure (dialysis ) & $3(1.0 \%)$ \\
\hline Any other complications & $5(1.8 \%)$ \\
\hline & \\
\hline
\end{tabular}

\section{DISCUSSION}

Our study shows that the factor most strongly related to risk of death from coronavirus was older age. Again male were more prone to risk as compared to female patients with the age group above 80 years.

Further the mortality rate showed a link between the patients of COVID-19 with other complication like diabetes mellitus. Sever acute respiratory syndrome of COVID -19 infection itself might represent a worsening factor for people with diabetes, as it can precipitate acute metabolic complications through direct negative effects on Beta cell function. There is experimental evidence of the effect of Diabetes and viral entry into the cell and inflammatory response to the infection. ${ }^{4,7}$

It was observed Diabetic patients have a confer increased risk for infections. Previous studies have shown a J-curve relationship between $\mathrm{HbA} 1 \mathrm{c}$ and risk of being admitted to hospital for infections in general and infections of the respiratory tract in particular. ${ }^{8,9}$

Patients with raised blood pressure have a twofold increased risk of dying from the coronavirus COVID-19 as compared to patients without blood pressure. Even patients with blood pressure, not taking the medication or changing the medications were also on high risk. 
In our study we also envisaged that Beedi and textile workers in Solapur district have been severely affected by coronavirus and byssinosis (occupational lung disease).

Other studies have noted abnormal liver and kidney function in COVID-19 patients, but whether it is due to drug injury or the disease is unknown, the authors said. "Considering the significant differences in the functional indexes of the liver and kidney, more attention should be paid to the monitoring and evaluation of liver and kidney function during the treatment of critically ill patients, " they wrote. $^{4,5}$

The figure 1 Depicts the phases of lockdown in Solapur city and COVID-19 cases with their mortality rate. Solapur experienced exponential growth of new cases since third lockdown phase. The average number of daily deaths from 1 to 274 till date.

\section{Phases of lockdown solapur (covid-19 positive cases and mortality )}

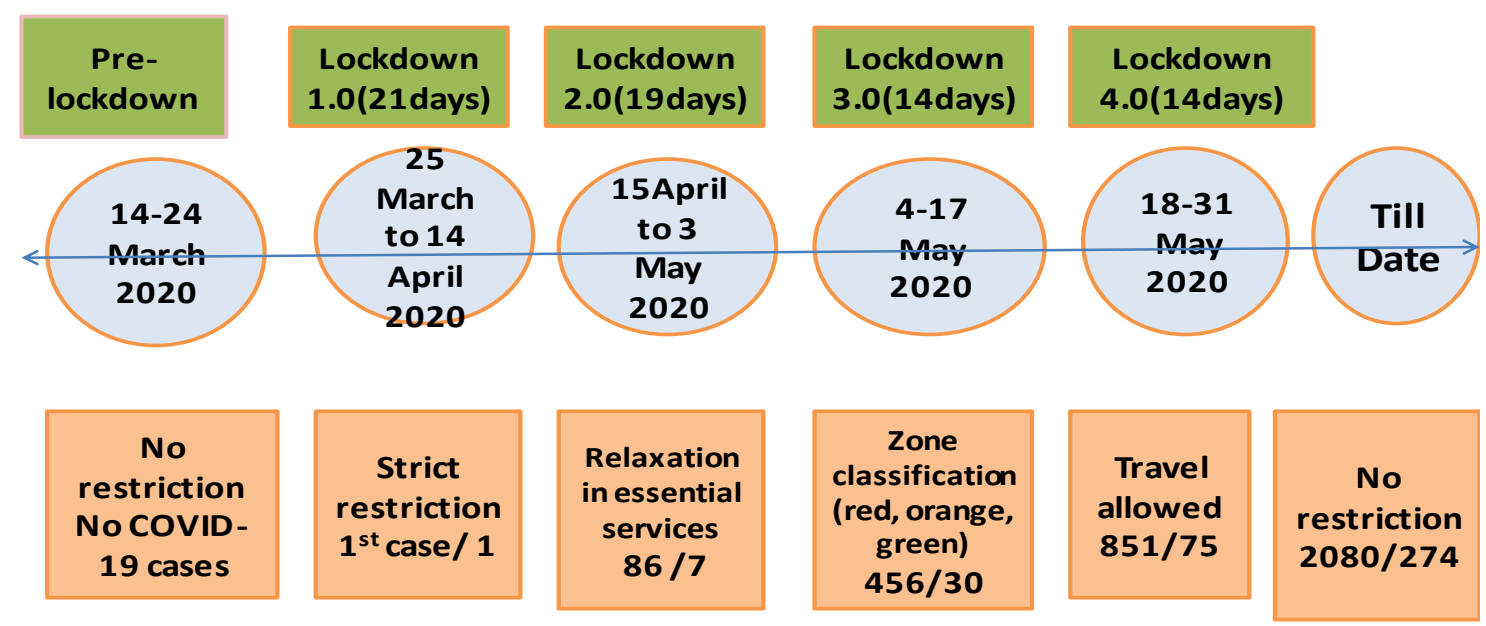

Figure 1: Phases of lockdown in Solapur

The evidence indicates that a significant proportion of people who died from Covid-19 were in a frail state and had significant co-morbidities. Only a small percentage had no pre-existing conditions. ${ }^{4}$.

Delays in the treatment of non-Covid-19 patients because of the health system cut back its non-essential services in order to redirect resources to deal with the pandemic and because 'coronaphobia' has led people to delay getting a diagnosis for other potentially serious illnesses.

Also Self-isolation during lockdown has contributed to an increase in alcohol and drug consumption by some people which might in turn reduce their life expectancy. ${ }^{6}$

With testing remaining low and many sick people avoiding hospitals, there is a danger of the death certificates not recording the correct cause of death and COVID-19 being missed.

Along with health and other frontline workers, vaccination in future must be prioritized for vulnerable populations, including elderly people. Not only elderly people with comorbidities should follow social distancing protection norms, such as mask, sanitization etc. but even the young people the around them should take precaution to prevent the transmission of infection and lower the mortality ratio.

\section{CONCLUSION}

In conclusion we revealed that mortality rate in Solapur is exuberantly increasing and the situation is turning worst. Our findings showed that most of the patients who died with COVID-19 were having many other complications. Diabetes mellitus itself contributed fifty three percent, whereas hypertensive patients thirty three percent. Apart from this there were patients with other complications also. This shows that the mortality rate in Solapur was high because of old age and comorbid patients.

Thus in the present scenario in order to control the death rate; it is a changing situation with clinician to treat the COVID-19 patients with comorbidities like diabetes mellitus and hypertension.

Ethics approval and consent to participate: This study was approved by the Institutional Ethical Committee, and each patient provided written informed consent form to donate blood sample after diagnostic procedures.

\section{Acknowledgements}

The authors wish to express their deepest gratitude to all the patients and healthy volunteers who have participated in this study. 


\section{REFERENCES}

1. Liu, J. et al. Longitudinal characteristics of lymphocyte responses and cytokine profiles in the peripheral blood of SARS-CoV-2 infected patients. EbioMedicine 2020;55:102763.

2. $\mathrm{Xu}, \mathrm{Z}$. et al. Pathological findings of COVID-19 associated with acute respiratory distress syndrome. Lancet Resp. Med. 2020;8:420-422.

3. Lundberg, S. et al. From local explanations to global understanding with explainable Al for trees. Nat. Mach. Intell. 2020;2:56-67.

4. Mao L, Wang M, Chen S, et al. Neurological Manifestations of Hospitalized Patients with COVID19 in Wuhan, China: a retrospective case series study. 2020.

5. ICMR. (2020, April 9, 2020). Strategy for COVID19 testing in India, Version 4 https://icmr.nic.in/sites/default/files/upload docum ents/Strategey for COVID19 Test v4 09042020.pdf
6. COVID19INDIA. (2020). COVID-19 India Dashboard. Retrieved May 29, 2020, from https://www.covid19india.org.

7. Dhillon, P., Kundu, S., Shekhar, C., Ram, U., Dwivedi, L. K., Yadav, S., \& Unisa, S. (2020). Case-Fatality Ratio and Recovery Rate of COVID-19: Scenario of Most Affected Countries and Indian States. Retrieved from https://iipsindia.ac.in/sites/default/files/iips_covid19 cfrr.pdf.

8. Organization WH. Clinical management of severe acute respiratory infection (SARI) when COVID-19 disease is suspected: interim guidance, 13 March 2020. World Health Organization, 2020.

9. Ai T, Yang Z, Hou H, Zhan C, Chen C, LvW, et al. Correlation of Chest CT and RT-PCR Testing in Coronavirus Disease. 2019. VID-19) in China: A Report of 1014 Cases. Radiology. 2020:200642.

10. Wang J-T, Sheng W-H, Fang C-T, Chen Y-C, Wang J-L, $\mathrm{Yu}$ C-J, et al. Clinical manifestations, laboratory findings, and treatment outcomes of SARS patients. Emerging infectious diseases. 2004;10(5):818.

Source of Support: None declared.

Conflict of Interest: None declared.

For any question relates to this article, please reach us at: editor@globalresearchonline.net

New manuscripts for publication can be submitted at: submit@globalresearchonline.net and submit_ijpsrr@rediffmail.com 